\title{
Novel Technique Combining Tissue and Mesh Repair for Umbilical Hernia in Adults
}

\author{
Ketan Vagholkar*, Suvarna Vagholkar \\ Department Of Surgery, Dr. D. Y. Patil Medical College, Navi Mumbai, India \\ Email: "kvagholkar@yahoo.com
}

Received 20 June 2014; revised 21 July 2014; accepted 18 August 2014

Copyright (C 2014 by authors and Scientific Research Publishing Inc.

This work is licensed under the Creative Commons Attribution International License (CC BY). http://creativecommons.org/licenses/by/4.0/

(c) $\underset{\mathrm{EY}}{\mathrm{EY}}$ Open Access

\begin{abstract}
Introduction: Umbilical hernia in adults poses a challenge to the surgeon. Understanding the anatomical and pathological intricacies of the hernia is pivotal in evolving a good repair. A multitude of repairs have been tried for repair of umbilical hernias. However none of them have withstood the test of time. Objective: The study aims at evolving a technique which provides mesh reinforced anatomical reconstruction of the defect. Materials and Methods: 20 patients underwent a combination repair for umbilical hernia. The results were tabulated and analysed. Results: None of the 20 patients developed any recurrence. Conclusion: A combined mesh reinforcement of tissue repair is advocated for umbilical hernias in adults.
\end{abstract}

\section{Keywords}

\section{Anatomical, Tissue, Mesh, Laparoscopic, Repair, Umbilical Hernia}

\section{Introduction}

Repair of umbilical hernia in adults is one of the commonest procedures performed on middle aged population. The traditional Mayo's repair is associated with increased failure rates. This has prompted surgeons to use mesh reinforcement. Laparoscopic approach has also emerged as one of the surgical options. However none of the aforementioned repairs can provide good long lasting results [1]. Therefore the need arises to develop a good repair which ensures a long term recurrence-free outcome.

\subsection{Objective}

Aim of the study was to develop a new technique which combines tissue repair with mesh reinforcement.

${ }^{*}$ Corresponding author. 


\subsection{Inclusion Criteria}

All adult patients diagnosed clinically with umbilical hernia.

\subsection{Exclusion Criteria}

- Patients who had undergone surgery previously around the umbilicus and had developed umbilical hernias.

- Complicated umbilical hernias.

\section{Material and Methods}

The study was conducted in a single surgical unit of Dr. D. Y. Patil hospital and research centre in Navi Mumbai in the period from January 2012 to June 2012. The study protocol was discussed and prior approval of the hospital ethics committee was sought. Patients diagnosed as umbilical hernia with well controlled comorbidities if present were included in the study. Patients were admitted one day prior to surgery. On admission, a detailed written informed consent was sought from each patient included in the study prior to the surgery. Thereafter a detailed proforma was completed which included demographic data and clinical details. Perioperative antibiotics were administered comprising 3 doses of intravenous Ceftriaxone $1 \mathrm{gm}$ and Amikacin $500 \mathrm{mg}$ (i.e. pre op, intra op and post op). All procedures were carried out under general anaesthesia. Patients were discharged after removal of drains and followed up.

\section{Surgical Technique}

All cases were operated upon by the first author. (KV) A vertical incision extending one inch above umbilicus to an inch below umbilicus, curving along the umbilicus to one side was made. The umbilical skin was dissected free from the underlying sac. The sac was dissected till the neck which was identified by a thick fibrous ring. The sac was opened, contents reduced and herniotomy performed (Figure 1). Two incisions were made $1 \mathrm{~cm}$ from midline on either rectus sheaths and flaps were created. The vertical extent of the incisions was 1 inch above to 1 inch below the level of the defect. These flaps were approximated in the midline with a non-absorbable suture material (Figure 2). A segment of the rectus muscle underlying these flaps was dissected free from the posterior rectus sheath in order to create a retro-rectus space. Polypropylene mesh altered to the size of the defect with an extra inch all around the defect was placed over newly created midline. It was fixed in midline and laterally with interrupted non-absorbable suture (Figure 3).

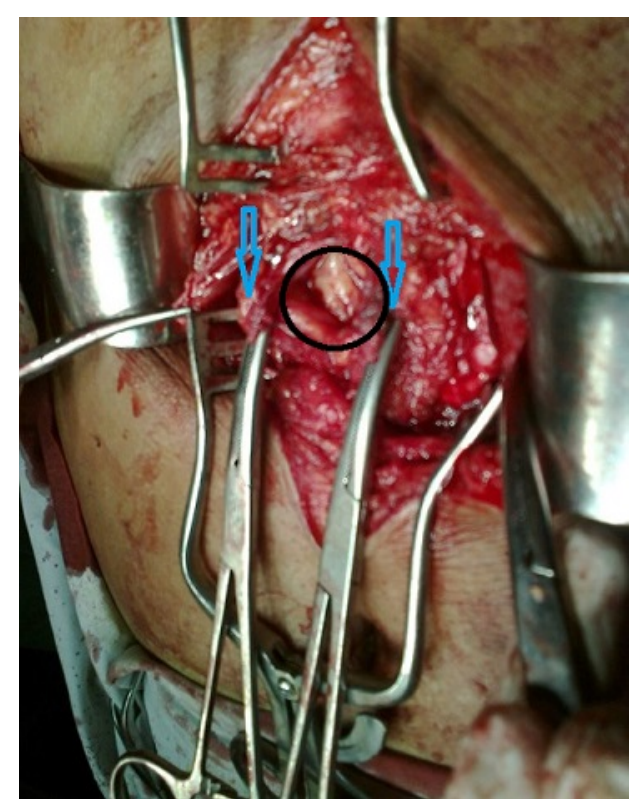

Figure 1. The defect is outlined by the black circle. The blue arrows point to the edges of the defect. 


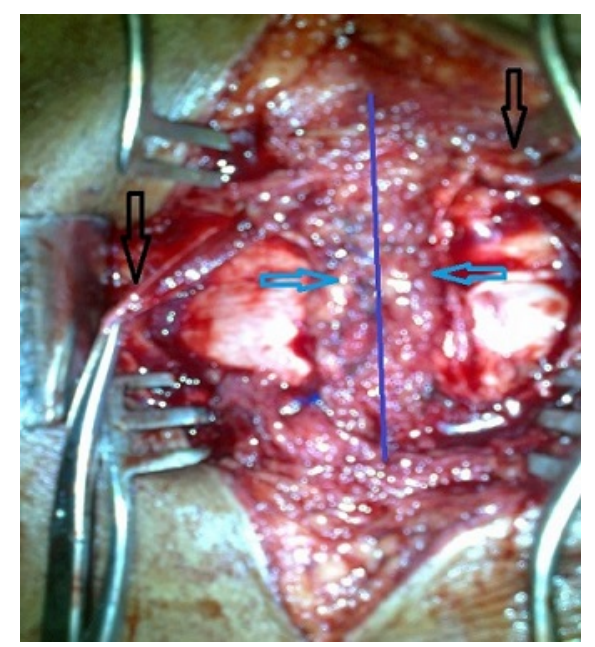

Figure 2. Reconstituted midline marked by the purple line after approximation of the medical cut edges of the anterior rectus flaps marked by blue arrows. The black arrows point towards the lateral cut edge of the anterior rectus sheath with the underlying rectus abdominis muscles on either side.

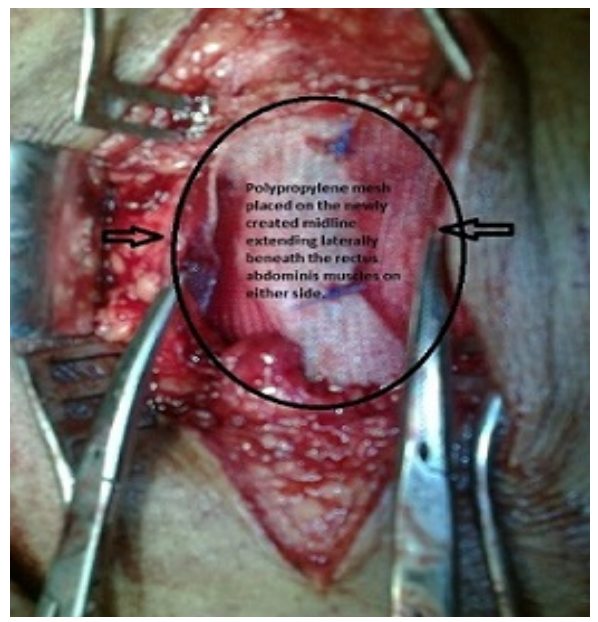

Figure 3. Mesh place over the newly created midline and extending underneath the rectus abdominis muscles on either side marked by the black arrows.

A negative suction drain was placed over mesh and brought out through a separate incision. The lateral cut edge of the anterior rectus sheath of either side was approximated with interrupted No. 1 Ethilon stitches (Figure 4). Subcutaneous tissues were approximated with absorbable suture taking utmost care to reconstitute the umbilical skin. Skin edges were approximated using a stapler.

Drains were removed after $48 \mathrm{hr}$ and patient discharged thereafter. Skin staples were removed on $10^{\text {th }}$ postoperative day. Patients were advised to use an abdominal binder for 12 weeks (Figure 5).

\section{Results}

The results of the study were tabulated (Table 1). The mean age of patients was $48.8 \pm$ SD of 5.5 yrs. (range 38 - 57 years). There were 17 females and 3 males who underwent this procedure. The mean BMI was 26.5 (range 25 - 29). Comorbidities observed in these patients were diabetes mellitus (DM) in 4, hypertension (HTN) in 4, IHD in 4 and 1 patient had ascites. 3 patients had all 3 comorbidities (DM, HT, and IHD) and 2 out of these 3 patients developed superficial wound infection, whereas 2 patients had HT and IHD and 1 patient had DM 


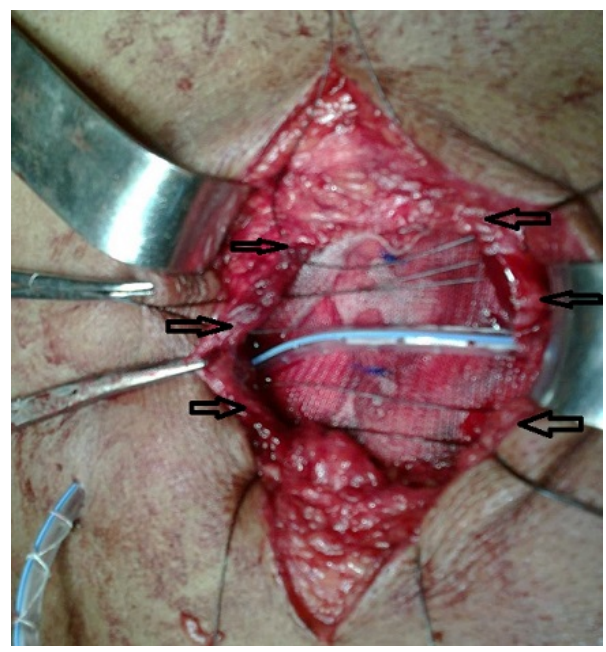

Figure 4. A negative suction drain placed over the mesh and brought out through a separate incision. The lateral cut edges of the anterior rectus sheath approximated with non absorbabale sutures marked by the black arrows.

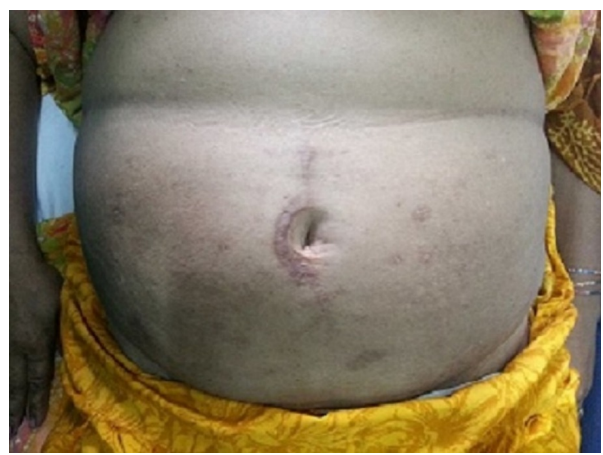

Figure 5. Final outcome.

with ascites. The mean stay of patients in hospital was 3.3 days (range 3 - 5 days). The mean follow up was 13 months (10 - 18 months). There was no recurrence in any of the patients with this technique.

\section{Discussion}

Attempts to evolve a standardized repair for umbilical hernia in the adult population still continue. A variety of techniques were developed for the repair [1] [2]. However most of these techniques did not sustain for long and gradually became obsolete. Obesity which has become a global epidemic especially in the urban population has become the biggest impediment to a successful outcome. Obesity happens to be important and significant factor in addition to age in development of umbilical hernias. Advancing age accompanied with obesity significantly predisposes to development of umbilical hernias. Umbilical hernias are also more commonly seen in female population. Weakening of abdominal wall after pregnancy heightens the incidence of umbilical hernia in women. This was observed in current study wherein the mean age of the patients was 48.8 yrs ( \pm SD of 5.5 ). $85 \%$ of patients in the present study were women and majority were obese (High BMI). Comorbidities such as DM, HT, IHD, ascites may impact surgical outcomes. This may be due to poor wound healing in diabetics and increased chances of developing hematomas in hypertensive patients. Patients with IHD may have ascites as seen in cardiac failure accompanied with poor vascularity of local tissues. Therefore developing a new technique needs to take into consideration intrinsic tissue factors which led to the development of the hernia along with extrinsic factors which create impediments to successful outcomes.

The traditional Mayo's repair comprises of horizontal double breasting of tissues withstood the test of time 
Table 1. Results of the case series.

\begin{tabular}{|c|c|c|c|c|c|c|c|c|c|c|c|}
\hline Sr. No & Age & Sex & BMI & $\mathrm{DM}$ & HT & IHD & Other & Infection & $\begin{array}{c}\text { Hosp. Stay } \\
\text { (Days) }\end{array}$ & $\begin{array}{c}\text { Follow Up } \\
\text { (Months) }\end{array}$ & Recurrence \\
\hline 1 & 45 & F & 26 & - & - & - & - & - & 3 & 13 & - \\
\hline 2 & 47 & F & 27 & - & - & - & - & - & 3 & 14 & - \\
\hline 3 & 48 & $\mathrm{~F}$ & 28 & - & - & - & - & - & 3 & 15 & - \\
\hline 4 & 49 & F & 25 & - & - & - & - & - & 3 & 17 & - \\
\hline 5 & 57 & F & 27 & - & - & - & - & - & 4 & 18 & - \\
\hline 6 & 46 & M & 28 & + & + & + & - & + & 3 & 15 & - \\
\hline 7 & 48 & F & 29 & + & + & + & - & + & 5 & 12 & - \\
\hline 8 & 56 & F & 25 & - & - & - & - & - & 3 & 14 & - \\
\hline 9 & 48 & F & 26 & - & - & - & - & - & 4 & 15 & - \\
\hline 10 & 47 & F & 27 & - & - & - & - & - & 3 & 12 & - \\
\hline 11 & 54 & $\mathrm{~F}$ & 27 & - & + & + & - & - & 4 & 10 & - \\
\hline 12 & 55 & $\mathrm{~F}$ & 26 & - & - & - & - & - & 3 & 12 & - \\
\hline 13 & 55 & $\mathrm{~F}$ & 28 & + & + & + & - & + & 4 & 12 & - \\
\hline 14 & 38 & $\mathrm{~F}$ & 26 & - & - & - & - & - & 3 & 10 & - \\
\hline 15 & 39 & $\mathrm{~F}$ & 27 & - & - & - & - & - & 3 & 12 & - \\
\hline 16 & 56 & $\mathrm{M}$ & 25 & - & - & - & - & - & 3 & 10 & - \\
\hline 17 & 44 & $\mathrm{~F}$ & 26 & - & - & - & - & - & 3 & 12 & - \\
\hline 18 & 55 & $\mathrm{~F}$ & 25 & - & - & - & - & - & 3 & 11 & - \\
\hline 19 & 44 & F & 25 & - & - & - & - & - & 3 & 11 & - \\
\hline 20 & 45 & $\mathrm{M}$ & 26 & + & - & - & + & - & 4 & 16 & - \\
\hline
\end{tabular}

(BMI: Body mass index; DM: Diabetes mellitus; HT: Hypertension; IHD: Ischaemic heart disease; Other: Ascites; F: Female; M: Male; +: Present; -: Absent).

for patients who are not obese. However in the obese subgroup of patients the failure rate with this technique started rising thereby prompting surgeons to devise another repair. The use of a mesh was therefore advocated. [2] [3]. The mesh however had its intrinsic complications. Because of anatomical intricacies of umbilical region, meshes were placed on the defect by onlay technique. This led to complications ranging from irritation caused by mesh to infections. Infections in the peri-umbilical region are common despite adequate prophylaxis. Infection developing in a hernia repair leads to complete failure with significant morbidity and cost implications [4] [5].

The advent of laparoscopy led to development of a technique for repair of umbilical hernias. Special non-absorbable adhesion-free meshes were placed intraperitoneally and fixed with tacks [2] [6] [7]. This approach has significant draw backs. Dissection of the sac may at times be difficult prompting conversion to open. The fibrous defect remains unobliterated and is just covered by mesh from within. There is high incidence of loosening of tacks thereby leading to collapse of mesh within peritoneal cavity. This predisposes to significantly morbid adhesive intestinal obstruction [6] [7].

Pain following laparoscopic umbilical hernia repair is a very morbid condition due to wide spread use of tacks. Laparoscopy does not offer any cosmetic advantage as the redundant umbilical skin remains untouched. Therefore laparoscopy as a procedure for umbilical hernia repair is not an attractive option as it lacks sound technical and cosmetic fundamentals [6].

The procedure presented in the study is based on the assumptions that in hernia patients there is a weakening of both the local aponeurotic structures and the process of healing.

The umbilicus is a potential weakness in the anterior abdominal wall. Exposure to high intra-abdominal pressure predisposes to give way of the umbilical cicatrix. This happens usually in the midline just above or below umbilical cicatrix. Hence, these hernias are designated as paraumbilical hernias in adults. The hernia sac which usually forms has a narrow neck thereby predisposing to complications. Therefore it is always advisable to re- 
pair such hernias at the earliest. As there is deficient midline in these patients at the site of herniation, it is essential to construct a midline [8]. This midline is created from flaps of anterior rectus sheath [8] [9]. Approximation of these flaps provides a strong midline (Figure 2). However as the tissues are intrinsically weak one cannot rely solely on the new midline created by these flaps [10] [11]. Thus it is prudent to reinforce the newly created midline with a mesh [12]-[15]. Therefore polypropylene mesh tailored to the size of the defect in each patient is used and fixed both in the midline and laterally. Laterally the mesh lies below the rectus abdominis muscles on either side (Figure 3). The space containing the mesh and rectus muscles is closed by the approximation of the lateral cut edges of anterior rectus sheath. A negative suction drain is placed over the mesh within the closed space in order to prevent development of hematomas and seromas which could predispose to increase tension within the space leading to break down of sutures [15] (Figure 4). The mesh remains sandwiched between anterior and posterior rectus sheath thereby reducing the chances of infection significantly [15].

The subcutaneous tissue needs to be approximated meticulously taking into consideration the cosmetic implications of the newly formed umbilicus [16] [17]. Skin is approximated with staples which help in providing a fine scar. This technique preserves the umbilicus which is a very important concern in female patients (Figure 5). 2 patients with significant comorbidities developed superficial wound infection which were cured by dressings only without any damage to the underlying repair. The mean hospital stay of patients was 3.35 days which is comparable to other studies [18] [19]. Patients were pain-free at the time of discharge. Mean follow up was 13 months with no recurrence in any of the patients. We therefore advocate this repair for umbilical hernias in adults as it has no recurrence rate. This repair is financially cheaper than a laparoscopic repair as the mesh used in this repair is an ordinary mesh unlike the one used during laparoscopic repair [20]. This is an added advantage for patients in the developing world where cost is a very important determinant of the approach to be used. The limitation in the study was the sample size. The technique needs to be carried out on a large sample size followed by a prospective randomized trial to weigh the benefits over other forms of repair.

\section{Conclusion}

This novel technique of mesh reinforcement of tissue repair is best suited for repair of umbilical hernias in adults in view of excellent results and low costs.

\section{Acknowledgements}

We would like to thank Dr. Shirish Patil, Dean of Dr. D. Y. Patil Medical College, Navi Mumbai, India for allowing us to publish this study. We would also like to thank Mr. Parth K. Vagholkar for his help in typesetting the manuscripts.

Funding: Nil.

Conflict of interest: Nil.

\section{References}

[1] Lau, H. and Patil, M.G. (2003) Umbilical Hernia in Adults. Surgical Endoscopy, 17, 2016-2020.

[2] Ponten, J.E., lenders, B.J., Charbon, J.A., Van de Poll, T.L., Heemskerk, J., Martinse, I.S., Konsten, J.L. and Mienhuis, S.W. (2014) Mesh or Patch for Hernia on Epigastric and Umbilical Sites (MORPHEUS Trial): Study Protocol for a Multicentre Patient Blinded Randomized Controlled Trial. BMC Surgery, 14, 33. http://dx.doi.org/10.1186/1471-2482-14-33

[3] Christofferson, M.W., Helgstrand, F., Rosenberg, J., Kehlet, H. and Bisgaard, T. (2013) Lower Reoperation Rate for Recurrence after Mesh versus Sutured Elective Repair in Small Umbilical and Epigastric Hernias. A Nationwide Register Study. World Journal of Surgery, 37, 2548-2552. http://dx.doi.org/10.1007/s00268-013-2160-0

[4] Read, R.C. (2002) Ventral Herniation in Adults. In: Zuidema, G.D. and Yeo, C.J. Eds., Shakelford's Surgery of the Alimentary Tract. 5th Edition, W.B. Sauders Company, Philadelphia, 150-164.

[5] Eryilmez, R., Sahin, M. and Tekelioglu, H. (2006) Which Repair in Umbilical Hernia of Adults: Primary or Mesh? International Surgery, 91, 258-261.

[6] Gonzalez, R., Mason, E., Duncan, J., Wilson, R. and Ramshaw, B.J. (2003) Laparoscopic versus Open Umbilical Hernia Repair. Journal of the Society of Laparoendoscopic Surgeons, 7, 323-328.

[7] Mason, R.J., Moazzez, A., Sohn, H.J., Berne, T.V. and Katkhouda, N. (2011) Laparoscopic versus Open Anterior Abdominal Wall Hernia Repair: 30 Day Morbidity and Mortality Using the ACS-NSQIP Database. Annals of Surgery, 
254, 641-652. http://dx.doi.org/10.1097/SLA.0b013e31823009e6

[8] Berger, R.L., Li, L.T., Hicks, S.C. and Liang, M.K. (2014) Suture versus Preperitoneal Polypropylene Mesh for Elective Umbilical Hernia Repair. Journal of Surgical Research. (Epub ahead of print).

[9] Nguyen, M.T., Berger, R.L., Hicks, S.C., Davila, J.A., Li, L.T., Kao, L.S. and Liang, M.K. (2014) Comparison of Outcome of Synthetic Mesh vs. Suture Repair of Elective Primary Ventral Herniorrhaphy: A Systematic Review and Meta-Analysis. JAMA Surgery, Epub ahead of print.

[10] Aslani, N. and Brown, C.J. (2010) Does Mesh Offer an Advantage over Tissue in the Open Repair of Umbilical Hernias? A Systematic Review and Meta-Analysis. Hernia, 14, 455-462. http://dx.doi.org/10.1007/s10029-010-0705-9

[11] Vychnevskaia, K., Mucci-Hennekinne, S., Casa, C., Brachet, D., Meunier, K., Briennon, X., Hammy, A. and Arnand, J.P. (2010) Intraperitoneal Mesh Repair of Small Ventral Abdominal Wall Hernias with a Ventralex Hernia Patch. Digestive Surgery, 27, 433-435. http://dx.doi.org/10.1159/000318783

[12] Berrevoet, F., D’Hont, F., Rogiers, X., Troisi, R. and de Hemptinne, B. (2011) Open Intraperitoneal versus Retromuscular Mesh Repair for Umbilical Hernia Less than 3 cm Diameter. American Journal of Surgery, 201, 85-90. http://dx.doi.org/10.1016/j.amjsurg.2010.01.022

[13] Tollens, T., Den Hondt, M., Devroe, K., Terry, C., Speybroeck, S., Aeloet, C. and Vanrykel, J.P. (2011) Retrospective Analysis of Umbilical, Epigastric and Small Incisional Hernia Repair Using Ventralex Hernia Patch. Hernia, 15, 531540. http://dx.doi.org/10.1007/s10029-011-0816-y

[14] Martin, D.F., Williams, R.F., Moolroney, T. and Voeller, G.R. (2008) Ventralex Mesh in Umbilical/Epigastric Hernia Repairs: Clinical Outcomes and Complications. Hernia, 12, 379-383. http://dx.doi.org/10.1007/s10029-008-0351-7

[15] Vagholkar, K. and Budhkar, A. (2014) Combined Tissue and Mesh Repair for Midline Incisional Hernia (A Study of 15 Cases). Journal of Medical Science and Clinical Research, 2, 1890-1900.

[16] Li, J., Ji, Z. and Zhang, Y. (2010) Open Ventral Hernia Repair with Kugel Patch. Saudi Medical Journal, 31, 668-671.

[17] Erritzee-Jervild, L., Christofferson, M.W., Helgstrand, F. and Bisgard, T. (2013) Long-Term Complaints after Elective Repair for Umbilical or Epigastric Hernias. Hernia, 17, 211-215. http://dx.doi.org/10.1007/s10029-012-0960-z

[18] Bisgaard, T., Kehlet, H., Bay-Nielsen, M., Iversen, M.G., Rosenberg, J. and Jorgensen, L.N. (2011) A Nationwide Study on Readmission, Morbidity and Mortality after Umbilical and Epigastric Hernia Repair. Hernia, 15, 541-546. http://dx.doi.org/10.1007/s10029-011-0823-z

[19] Maly, O. and Sotona, O. (2014) Long-Term Follow-Up Results after Open Small Umbilical Hernia Repairs. Rozhledy v Chirurgii, 93, 208-211.

[20] Venclausken, L., Silanskaite, J. and Kiudelis, M. (2008) Umbilical Hernia: Factors Indicative of Recurrence. Medicina (Kaunas, Lithuania), 44, 855-859. 
Scientific Research Publishing (SCIRP) is one of the largest Open Access journal publishers. It is currently publishing more than 200 open access, online, peer-reviewed journals covering a wide range of academic disciplines. SCIRP serves the worldwide academic communities and contributes to the progress and application of science with its publication.

Other selected journals from SCIRP are listed as below. Submit your manuscript to us via either submit@scirp.org or Online Submission Portal.
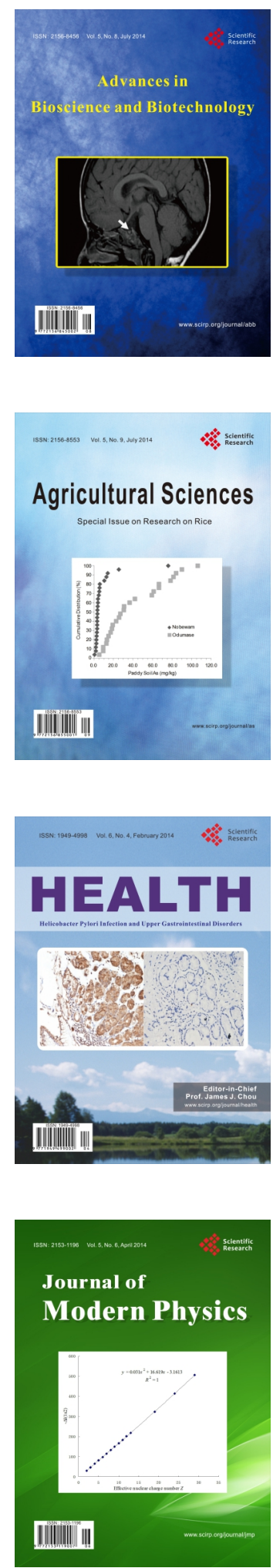
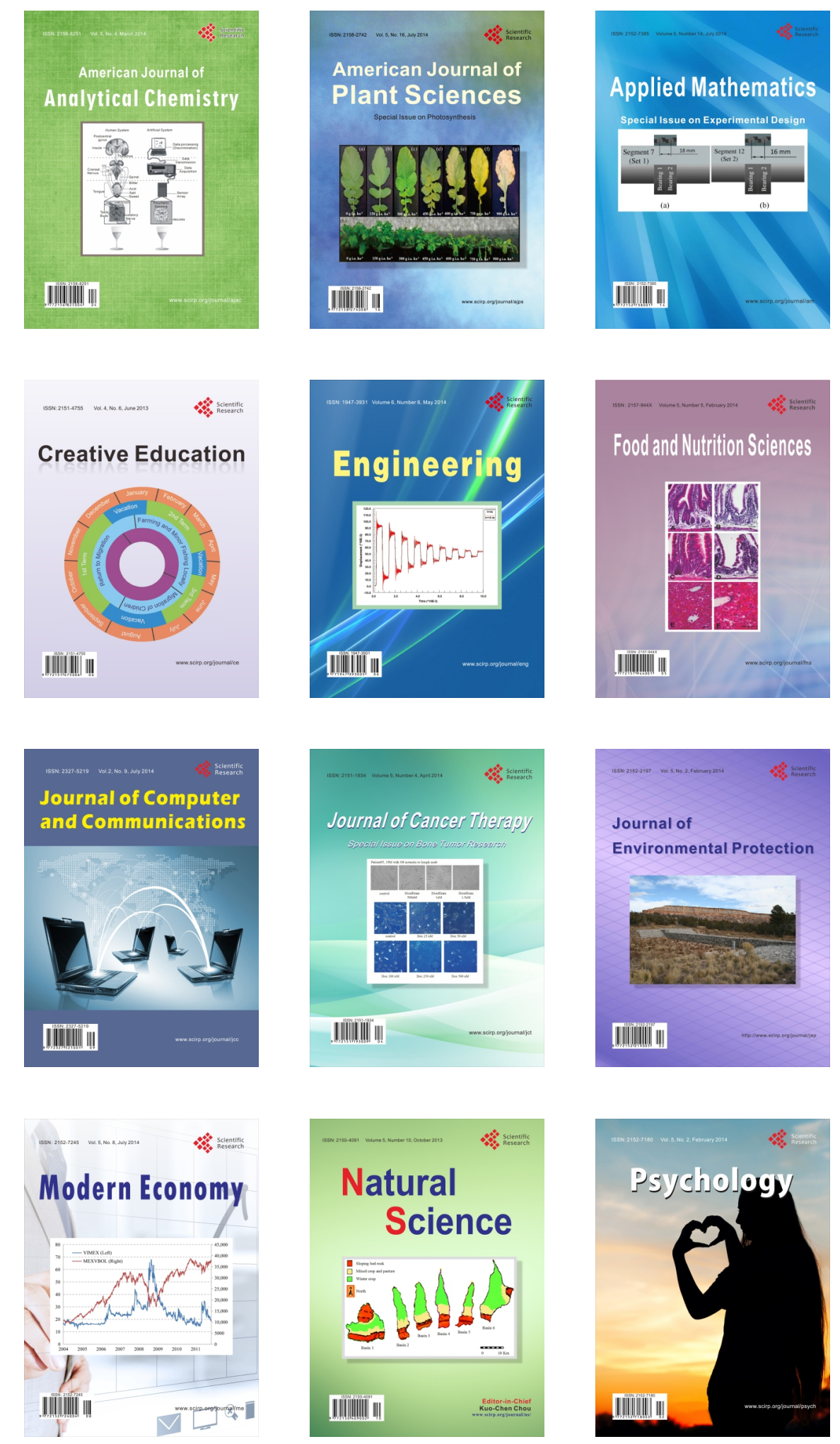